\title{
Liver Profile of Atazanavir/Ritonavir in Pregnant Albino Rats
}

\author{
Elias Adikwu $^{1, *}$, James Kemelayefa ${ }^{1}$, Winifred Ocheiga ${ }^{2}$ \\ ${ }^{1}$ Department of Pharmacology and Toxicology, Faculty of Pharmacy, Niger Delta University, Bayelsa State, Nigeria \\ ${ }^{2}$ Department of Pharmacology and Toxicology, Faculty of Pharmacy, Madonna University, Rivers State, Nigeria \\ Corresponding author* \\ adikwuelias@gmail.com
}

\begin{abstract}
Medication use during pregnancy is challenging due to the occurrence of maternal or fetal toxicities. Atazanavir/ritonavir (ATV/r) has hepatotoxic potential hence; use in pregnant patients living with human immunodeficiency virus may cause maternal hepatotoxicity. This study assessed the liver profile of ATV/r in pregnant albino rats. Thirty pregnant albino rats randomized into groups were orally treated daily with ATV/r (4.28/1.43 mg/kg-34.3/11.4 mg/kg) for 16 days. After treatment, the rats were weighed and sacrificed. Blood samples were collected and examined for serum biochemical parameters. Liver samples were weighed and assessed for biochemical and histological changes. Body and liver weights were normal $(\mathrm{p}>0.05)$ in ATV/r-treated pregnant rats when compared to control. Serum total cholesterol, triglyceride, low density lipoprotein cholesterol and blood glucose levels were significantly $(\mathrm{p}<0.01)$ elevated whereas high density lipoprotein cholesterol level was significantly $(\mathrm{p}<0.01)$ decreased in rats treated with ATV/r $(34.3 / 11.4 \mathrm{mg} / \mathrm{kg}) \mathrm{when}$ compared to control. Liver and serum aminotransferases, alkaline phosphatase, gamma-glutamyl transferase, lactate dehydrogenase, total bilirubin, and conjugated bilirubin levels were significantly increased in a dose-dependent fashion in rats treated with ATV/r; 8.57/2.86 mg/kg (p<0.05), $17.1 / 5.72 \mathrm{mg} / \mathrm{kg}(\mathrm{p}<0.01)$ and 34.3/11.4 mg/kg ( $<0.001)$ when compared to control. Liver superoxide dismutase, catalase, glutathione and glutathione peroxidase levels were significantly decreased whereas malondialdehyde levels were significantly increased in a dosedependent fashion in rats treated with ATV/r; 8.57/2.86 mg/kg ( $<<0.05), 17.1 / 5.72 \mathrm{mg} / \mathrm{kg}(\mathrm{p}<0.01)$ and $34.3 / 11.4 \mathrm{mg} / \mathrm{kg}(\mathrm{p}<0.001)$ when compared to control. Necrotic hepatocytes were observed at higher doses of ATV/r. ATV/r may not be hepatotoxic in pregnant women living with HIV at the clinical dose.
\end{abstract}

Keywords: Atazanavir/ritonavir; pregnancy; liver; toxicity; rat

\section{INTRODUCTION}

Human immunodeficiency (HIV) infection is a leading cause of maternal and neonatal morbidity and mortality (Abdol-Karim et al., 2010). Pregnancy, whether actual or anticipated, has been a critical driver for the diagnosis, treatment and care of women living with HIV to prevent transmission from mother to child. This necessitates the use of highly active antiretroviral therapy (HAART) in pregnant women living with HIV and neonates exposed to HIV. This strategy has drastically reduced mother to child transmission of HIV (Coovadia et al., 2007). Most HAART have demonstrated favorable safety profiles for mothers and infants during trial follow-up (Coovadia et al., 2007). However, toxicities have been reported in some quarters with growing concern on hepatotoxicity in pregnant women (Bera et al., 2012). The use of medication during pregnancy has been a serious clinical challenge in terms of maternal and fetal safety due to physiological changes and complications that do arise during pregnancy. Hepatitis, intrahepatic cholestasis, and acute fatty liver, are some complications that may occur during pregnancy (Hammoud et al., 2014). Also, pregnancy could increase the incidence of treatment related adverse effect including hepatotoxicity (Joy et al., 2015; Clark,
2015) and has a significant impact on the efficacy and safety of a drug (Abduljalil et al., 2012). Atazanavir/ritonavir (ATV/r) is use as a component of HAART in the management of HIV (Mandelbrot et al., 2011). Its use in HIV management has decreased mortality associated with HIV. It has a high genetic barrier to resistance, favorable adherence profile and low effects on lipids and glucose metabolism (Achenbach et al., 2011). However, it has been associated with hyperglycemia, alterations in cardiac conduction and renal toxicity (Clayden, 2009; Conradie et al., 2011; Hamada et al., 2012). Furthermore, elevations in serum liver enzymes and indirect hyperbilirubinemia have been reported hence, use in pregnant women living with HIV raises toxicological concern such as hepatotoxicity (Eholié et al., 2013). This study assessed the liver profile of ATV/r in a pregnant albino rat model.

\section{MATERIAL AND METHODS}

\section{Animal and Drugs}

Pregnant albino rats $(200 \mathrm{~g}-250 \mathrm{~g})$ used for this study were obtained from the animal house of the Department of Pharmacology and Toxicology, Madonna University, Nigeria. The rats were housed under room temperature 
with a 12:12 light: dark cycle. The rats were randomized into 6 rats per cage according to their weights and had free access to diet and water. ATV/r used for this study was manufactured by Mylan laboratories limited India. The doses of ATV/r (4.28/1.43, 8.57/2.86, 17.1/5.72, and $34.3 / 11.4 \mathrm{mg} / \mathrm{kg}$ ) used for this study represent clinical dose, 2, 4, and 8, times the clinical dose respectively (von Hentig et al., 2007).

\section{Experimental protocol}

The reproductive status and estrous period of the rats were determined by obtaining their virginal smears. After two complete regular cycles, timed mating of female rats was done on the night of the pro-estrous $(\mathrm{N})$ phase of the cycle. In the morning following mating, vaginal smears were taken again. The presence of spermatozoa and squamus cells in the smear confirmed mating and fertilization of ovule. The sperm - positive morning was thus designated day 0 of pregnancy. Thirty pregnant albino rats used were weighed and divided into five groups labeled A-E of six rats each. Group A (Control) orally received normal saline $(0.2 \mathrm{~mL})$ whereas groups B-E orally received ATV $/ \mathrm{r}(4.28 / 1.43 \mathrm{mg} / \mathrm{kg}$, $8.57 / 2.86 \mathrm{mg} / \mathrm{kg}, 17.1 / 5.72 \mathrm{mg} / \mathrm{kg}$ and $34.3 / 11.4 \mathrm{mg} / \mathrm{kg}$ ) daily for 16 days respectively.

\section{Collection of samples and biochemical analyses}

The rats were sacrificed on day 17 after exposure to inhalational diethyl ether. Blood samples were collected and centrifuged at $1200 \mathrm{~g}$ for 15 minutes and sera extracted. Sera were analyzed for biochemical parameters. Liver samples were collected, weighed and washed in a cold $1.15 \% \mathrm{KCl}$ solution and homogenized in $0.1 \mathrm{M}$ Tris- $\mathrm{HCl}$ buffer, $\mathrm{pH}$ 7.4. The homogenates were centrifuged at $1200 \mathrm{~g}$ speed for 15 minutes and the supernatants were collected and evaluated for biochemical parameters. Alanine aminotransferase (ALT), aspartate aminotransferase (AST), alkaline phosphatase (ALP), gamma-glutamyl transferase (GGT), lactate dehydrogenase (LDH), total bilirubin (TB), conjugated bilirubin (CB), triglyceride (TG), total cholesterol (TC), and high density lipoprotein cholesterol (HDL-C) were evaluated using commercial test kits (Randox Diagnostics, Crumlin, UK). Blood glucose (G) was estimated with the aid of a glucometer whereas low density lipoprotein cholesterol (LDL-C) was estimated as reported by Friedewald et al. (1972). Liver superoxide dismutase (SOD) was determined as described by Sun and Zigma, (1978). Catalase (CAT) was assayed according to Aebi, (1984). Glutathione (GSH) was estimated according to Sedlak and Lindsay, (1968). Malondialdehyde (MDA) was determined as reported by Buege and Aust, (1978). The method of
Rotruck et al. (1973) was used for the evaluation of glutathione peroxidase (GPx) whereas total protein was evaluated according to Gonall et al. (1949).

\section{Histological examination of the liver}

Liver samples were collected, cleaned and weighed. Liver samples were fixed in $10 \%$ buffered neutral formalin for $24 \mathrm{~h}$. Liver samples were dehydrated in increasing ethanol concentrations and mounted in paraffin block. Paraffin sections $(3-5 \mu \mathrm{m})$ were prepared, deperaffinized and stained with hematoxylin and eosin dye (H\&E). Stained sections were examined using a light microscope for histological changes.

\section{Statistical analysis}

Results are expressed as mean \pm SEM and were evaluated using one way analysis of variance (ANOVA) followed by Dunnett's post hoc tests. Results were considered to be significant at $\mathrm{p}<0.05 ; 0.01 ; 0.001$.

\section{RESULTS}

The body and liver weights of pregnant rats treated with ATV/r were not significantly ( $p>0.05)$ different when compared to control (Table 1). Significant increases in a dose-dependent fashion occurred in the liver and serum AST, ALT, ALP, GGT, LDH, TB and CB levels in rats treated with ATV/r (Tables 2 and 3). The increases in the levels of the aforementioned parameters were not significant $(p>0.05)$ at the clinical dose $(4.28 / 1.43$ $\mathrm{mg} / \mathrm{kg}$ ), but were significant at $8.57 / 2.86 \mathrm{mg} / \mathrm{kg}$ $(\mathrm{p}<0.05), 17.1 / 5.72 \mathrm{mg} / \mathrm{kg}(\mathrm{p}<0.01)$ and $34.3 / 11.4 \mathrm{mg} / \mathrm{kg}$ $(\mathrm{p}<0.001)$ when compared to control (Tables 2 and 3 ). Serum TG, TC, LDL-C and blood G levels were significantly $(p<0.01)$ increased whereas serum HDL-C level was significantly $(\mathrm{p}<0.01)$ decreased in pregnant rats treated with ATV/r $(34.3 / 11.4 \mathrm{mg} / \mathrm{kg})$ when compared to control (Table 4). Treatment with ATV/r produced decreases in liver SOD, CAT, GSH and GPx levels with increases in MDA levels in a dose-dependent fashion (Table 5). The effects on liver SOD, CAT, GSH, GPx and MDA levels were not significant $(p>0.05)$ at the clinical dose $(4.28 / 1.43 \mathrm{mg} / \mathrm{kg})$, but were significant at $8.57 / 2.86 \mathrm{mg} / \mathrm{kg}(\mathrm{p}<0.05), 17.1 / 5.72 \mathrm{mg} / \mathrm{kg}(\mathrm{p}<0.01)$ and $34.3 / 11.4 \mathrm{mg} / \mathrm{kg} \quad(\mathrm{p}<0.001)$ when compared to control (Table 5). The liver of control rat showed normal hepatocytes (Figure A). The liver of rats treated with ATV $/ \mathrm{r}(4.28 / 1.43 \mathrm{mg} / \mathrm{kg})$ showed inflammatory cell infiltration (Figure B). In contrast, the liver of rats treated with ATV/r; $8.57 / 2.86 \mathrm{mg} / \mathrm{kg}, 17.1 / 5.74 \mathrm{mg} / \mathrm{kg}$ and 34.3/11.4 mg/kg showed hepatocyte necroses respectively (Figures C, D and E). 
Table 1. Effects of atazanavir/ritonavir on body and liver weights of pregnant albino rats.

\begin{tabular}{cccc}
\hline Group & Body weight $(\mathbf{g})$ & Absolute liver weight $(\mathbf{g})$ & Relative liver weight $(\%)$ \\
\hline A & $250.7 \pm 12.4$ & $7.88 \pm 1.14$ & $3.15 \pm 0.27$ \\
B & $257.6 \pm 13.2$ & $7.58 \pm 1.65$ & $2.95 \pm 0.14$ \\
C & $255.1 \pm 10.9$ & $7.46 \pm 0.57$ & $2.93 \pm 0.09$ \\
D & $260.6 \pm 11.2$ & $7.91 \pm 0.32$ & $3.04 \pm 0.43$ \\
E & $250.4 \pm 10.7$ & $7.80 \pm 1.42$ & $3.12 \pm 0.83$ \\
\hline
\end{tabular}

$\mathrm{TV} / \mathrm{r}=$ Atazanavir/ritonavir, Data are expressed as mean \pm SEM. $\mathrm{n}=6$

Table 2. Effect of atazanavir/ritonavir on serum liver function parameters of pregnant albino rats.

\begin{tabular}{cccccccc}
\hline Group & $\mathbf{A S T}(\mathbf{U} / \mathbf{L})$ & $\mathbf{A L T}(\mathbf{U} / \mathbf{L})$ & $\mathbf{A L P}(\mathbf{U} / \mathbf{L})$ & $\mathbf{G G T}(\mathbf{U} / \mathbf{L})$ & $\mathbf{L D H}(\mathbf{U} / \mathbf{L})$ & $\mathbf{C B}(\mathbf{g} / \mathbf{d L})$ & $\mathbf{T B}(\mathbf{g} / \mathbf{d L})$ \\
\hline A & $45.5 \pm 3.99$ & $34.2 \pm 2.15$ & $47.3 \pm 3.56$ & $48.5 \pm 3.12$ & $0.73 \pm 0.04$ & $4.50 \pm 0.18$ & $8.54 \pm 0.71$ \\
B & $50.3 \pm 3.46$ & $38.8 \pm 2.25$ & $51.9 \pm 4.06$ & $52.1 \pm 4.00$ & $0.80 \pm 0.02$ & $4.87 \pm 0.25$ & $9.01 \pm 0.36$ \\
C & $66.7 \pm 5.00^{\mathrm{a}}$ & $45.8 \pm 4.70^{\mathrm{a}}$ & $70.4 \pm 5.36^{\mathrm{a}}$ & $78.2 \pm 5.31^{\mathrm{a}}$ & $1.31 \pm 0.19^{\mathrm{a}}$ & $6.44 \pm 1.22^{\mathrm{a}}$ & $12.7 \pm 1.11^{\mathrm{a}}$ \\
D & $96.3 \pm 7.87^{\mathrm{b}}$ & $63.3 \pm 2.62^{\mathrm{b}}$ & $99.4 \pm 8.66^{\mathrm{b}}$ & $121.1 \pm 10.6^{\mathrm{b}}$ & $1.90 \pm 0.12^{\mathrm{b}}$ & $8.95 \pm 1.06^{\mathrm{b}}$ & $15.5 \pm 1.40^{\mathrm{b}}$ \\
E & $140.6 \pm 10.3^{\mathrm{c}}$ & $128.8 \pm 7.00^{\mathrm{c}}$ & $155.3 \pm 10.3^{\mathrm{c}}$ & $180.4 \pm 12.5^{\mathrm{c}}$ & $2.60 \pm 0.52^{\mathrm{c}}$ & $13.3 \pm 1.01^{\mathrm{c}}$ & $23.5 \pm 2.22^{\mathrm{c}}$ \\
\hline
\end{tabular}

ATV/r: Atazanavir/ritonavir, ALT: Alanine aminotransferase, ALP: Alkaline phosphatase, AST: Aspartate aminotransferase, GGT: Gamma-glutamyl transferase, LDH: Lactate dehydrogenase, CB: Conjugated bilirubin, TB: Total bilirubin. Data are expressed as mean \pm SEM. $\mathrm{n}=6 .{ }^{a}$ Differ significantly $(\mathrm{p}<0.05)$ when compared to control, ${ }^{\mathrm{b}}$ Differ significantly $(\mathrm{p}<0.01)$ when compared to control, ${ }^{\mathrm{c}}$ Differ significantly ( $\left.<<0.001\right)$ when compared to control.

Table 3. Effect of atazanavir/ritonavir on some biochemical parameters in the liver tissue of pregnant albino rats.

\begin{tabular}{cccccc}
\hline Group & ALT(U/L) & AST(U/L) & ALP(U/L) & GGT(U/L) & LDH(U/L) \\
\hline A & $185.0 \pm 15.5$ & $173.8 \pm 14.1$ & $187.2 \pm 15.34$ & $192.5 \pm 12.2$ & $3.25 \pm 0.18$ \\
B & $200.5 \pm 19.1$ & $211.2 \pm 16.1$ & $201.4 \pm 11.4$ & $224.7 \pm 16.2$ & $3.76 \pm 0.12$ \\
C & $321.3 \pm 20.2^{\mathrm{a}}$ & $338.2 \pm 22.2^{\mathrm{a}}$ & $351.0 \pm 18.4^{\mathrm{a}}$ & $330.1 \pm 20.6^{\mathrm{a}}$ & $4.84 \pm 0.85^{\mathrm{a}}$ \\
D & $463.8 \pm 22.6^{\mathrm{b}}$ & $548.1 \pm 18.7^{\mathrm{b}}$ & $474.2 \pm 19.0^{\mathrm{b}}$ & $580.1 \pm 17.1^{\mathrm{b}}$ & $6.95 \pm 0.32^{\mathrm{b}}$ \\
E & $695.2 \pm 27.4^{\mathrm{c}}$ & $789.2 \pm 20.6^{\mathrm{c}}$ & $690.0 \pm 21.9^{\mathrm{c}}$ & $768.8 \pm 22.8^{\mathrm{c}}$ & $9.97 \pm 0.71^{\mathrm{c}}$ \\
\hline
\end{tabular}

ATV/r: Atazanavir/ritonavir, ALT: Alanine aminotransferase, ALP: Alkaline phosphatase, AST: Aspartate aminotransferase, GGT: Gamma-glutamyl transferase, LDH: Lactate dehydrogenase. Data are expressed as mean \pm SEM. $n=6$. ${ }^{a}$ Differ significantly $(\mathrm{p}<0.05)$ when compared to control, ${ }^{b}$ Differ significantly $(\mathrm{p}<0.01)$ when compared to control, ${ }^{\mathrm{c}}$ Differ significantly $(\mathrm{p}<0.001)$ when compared to control.

Table 4. Effect of atazanavir/ritonavir on lipid profile of pregnant albino rats.

\begin{tabular}{|c|c|c|c|c|c|}
\hline Group & $\mathbf{G}(\mathrm{mg} / \mathrm{dL})$ & TG(mg/dL) & TC(mg/dL) & HDL-C (mg/dL) & LDL-C (mg/dL) \\
\hline A & $95.0 \pm 6.41$ & $70.5 \pm 6.78$ & $110.1 \pm 12.8$ & $30.7 \pm 3.44$ & $65.7 \pm 6.00$ \\
\hline B & $92.0 \pm 9.00$ & $74.9 \pm 6.70$ & $112.0 \pm 13.6$ & $32.6 \pm 2.61$ & $64.5 \pm 6.42$ \\
\hline $\mathrm{C}$ & $89.3 \pm 6.42$ & $73.2 \pm 7.53$ & $109.8 \pm 12.0$ & $32.5 \pm 3.72$ & $63.8 \pm 5.11$ \\
\hline $\mathrm{D}$ & $100.9 \pm 9.19$ & $81.1 \pm 7.56$ & $110.3 \pm 11.1$ & $29.4 \pm 2.63$ & $65.7 \pm 7.62$ \\
\hline $\mathrm{E}$ & $152.0 \pm 8.00^{\mathrm{a}}$ & $132.7 \pm 9.21^{\mathrm{a}}$ & $161.0 \pm 14.1^{\mathrm{a}}$ & $21.3 \pm 2.10^{\mathrm{a}}$ & $113.4 \pm 8.32^{\mathrm{a}}$ \\
\hline
\end{tabular}

Data are express as mean \pm SEM. $n=6$ G: Glucose, TG: Triglyceride TC: Total cholesterol HDL-C: High density lipoprotein cholesterol, LDL-C: Low density lipoprotein cholesterol. ${ }^{a}$ Significant $(\mathrm{p}<0.01)$ when compared to control

Table 5. Effect of atazanavir/ritonavir on liver oxidative stress indices of pregnant albino rats.

\begin{tabular}{cccccc}
\hline Group & $\begin{array}{c}\text { MDA } \\
(\mathbf{n m o l} / \mathbf{m g} \text { protein) }\end{array}$ & $\begin{array}{c}\text { SOD } \\
(\mathbf{U} / \mathbf{m g} \text { protein) }\end{array}$ & $\begin{array}{c}\text { CAT } \\
(\mathbf{U} / \mathbf{m g} \text { rotein) }\end{array}$ & $\begin{array}{c}\text { GSH } \\
(\boldsymbol{\mu m o l} / \mathbf{m g} \text { protein) }\end{array}$ & $\begin{array}{c}\text { GPX } \\
(\mathbf{U} / \mathbf{m g} \text { protein) }\end{array}$ \\
\hline A & $0.32 \pm 0.05$ & $16.2 \pm 2.09$ & $26.4 \pm 3.77$ & $8.97 \pm 0.15$ & $9.44 \pm 0.12$ \\
B & $0.36 \pm 0.01$ & $14.6 \pm 1.04$ & $23.6 \pm 2.87$ & $8.25 \pm 0.70$ & $9.10 \pm 0.12$ \\
C & $0.50 \pm 0.08^{\mathrm{a}}$ & $10.4 \pm 1.06^{\mathrm{a}}$ & $15.5 \pm 3.05^{\mathrm{a}}$ & $5.88 \pm 0.54^{\mathrm{a}}$ & $7.42 \pm 0.34^{\mathrm{a}}$ \\
D & $0.68 \pm 0.03^{\mathrm{b}}$ & $7.06 \pm 1.15^{\mathrm{b}}$ & $10.6 \pm 1.37^{\mathrm{b}}$ & $3.10 \pm 0.79^{\mathrm{b}}$ & $5.02 \pm 0.44^{\mathrm{b}}$ \\
E & $0.98 \pm 0.01^{\mathrm{c}}$ & $3.16 \pm 0.27^{\mathrm{c}}$ & $20.5 \pm 3.07^{\mathrm{c}}$ & $1.06 \pm 0.58^{\mathrm{c}}$ & $2.11 \pm 0.53^{\mathrm{c}}$ \\
\hline
\end{tabular}

ATV/r: Atazanavir/ritonavir, MDA: Malondialdehyde, CAT: Catalase, GSH: Glutathione, SOD: Superoxide dismutase, GPx: Glutathione peroxidase. Data are expressed as mean \pm SEM. $n=6$. ${ }^{a}$ Differ significantly $(\mathrm{p}<0.05)$ when compared to control, ${ }^{b}$ Differ significantly $(\mathrm{p}<0.01)$ when compared to control, ${ }^{c}$ Differ significantly $(\mathrm{p}<0.001)$ when compared to control 

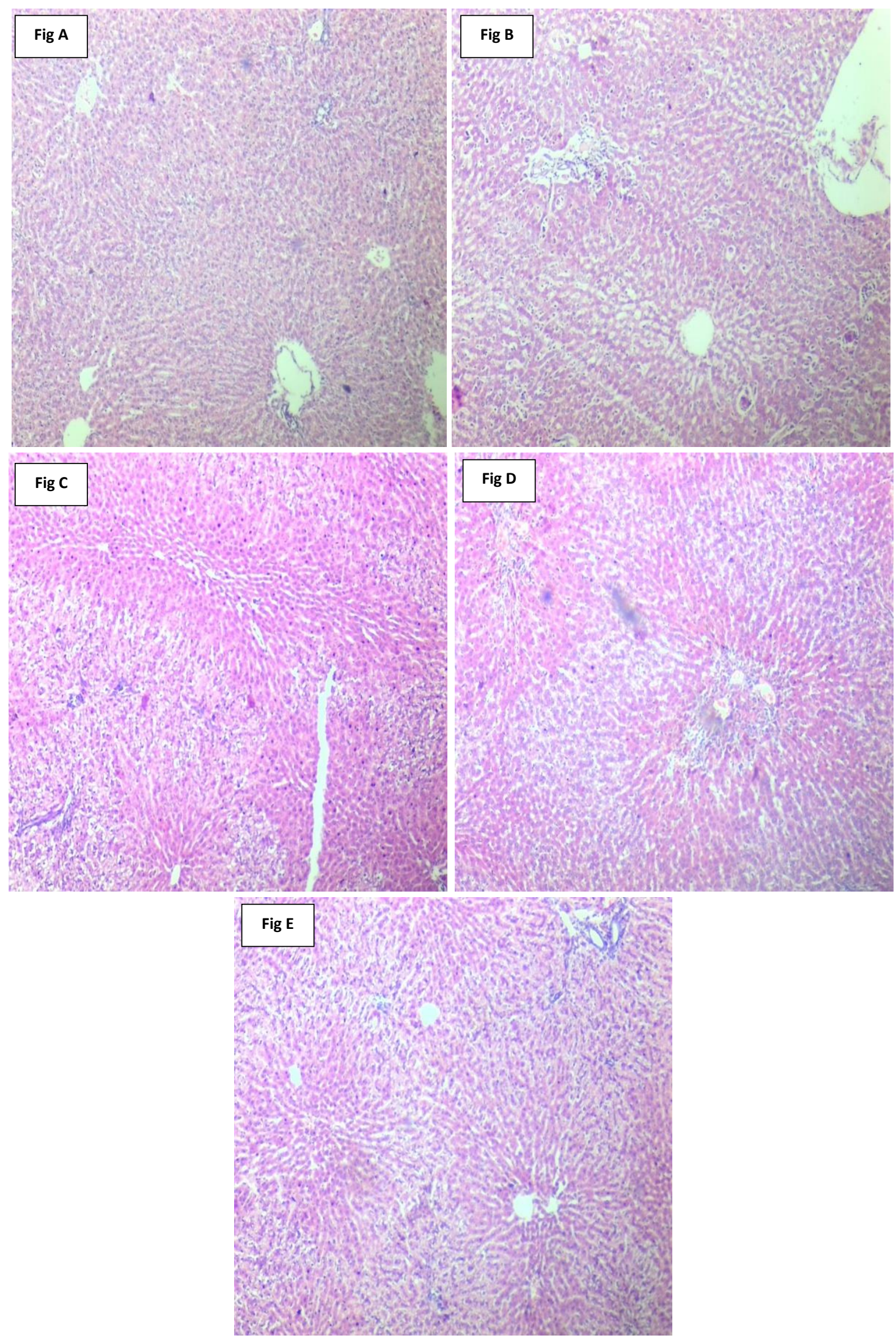

Figure 1. Fig A: Liver of control pregnant albino rat showing normal hepatocytes. Fig B: Liver of pregnant albino rat treated with ATV/r (4.28/1.43 $\mathrm{mg} / \mathrm{kg}$ ) showing inflammatory cell infiltration. Fig C: Liver of pregnant albino rat treated with ATV/r $(8.57 / 2.86 \mathrm{mg} / \mathrm{kg})$ showing hepatocyte necrosis. Fig D: Liver of pregnant albino rat treated with ATV/r (17.1/5.74 mg/kg) showing hepatocyte necrosis. Fig E: Liver of pregnant albino rat treated with ATV/r (34.2/11.4 mg/kg) showing hepatocyte necrosis. (H and E X100). 


\section{DISCUSSION}

Drug-induced liver injury is a potential complication of nearly every prescribed drug and many fatal and nearfatal drug reactions occurred each year (Lee, 1995). Pregnancy-related liver disease is the most frequent cause of liver dysfunction in pregnancy and provides a real threat to fetal and maternal survival (Joshi, 2010) and could be aggravated by some medications (Eyal et al., 2010). This makes the provision of antiretroviral therapy during pregnancy a serious clinical challenge due to the possible occurrence of hepatotoxicity. The present study evaluated the liver profile of ATV/r in pregnant albino rats. The evaluation of organ weight in toxicology studies is an integral component in the assessments of pharmaceuticals, chemicals, and medical devices (Wooley, 2003). This study did not observe significant changes in the body and liver weights of ATV/r-treated pregnant rats. Serum TG, TC, LDL-C, HDL-C and blood $G$ levels are yardsticks for hyperlipidemia and hyperglycemia caused by drugs (Ehigiator and Adikwu, 2019). This study, observed elevated levels of serum TG, TC, LDLC and blood G with decreased HDLC level at the highest ATV/r dose. These observations are possible signs of hyperlidemia and hyperglycemia (Ehigiator and Adikwu, 2019). The serum levels of ALT, AST, ALP, LDH and GGT are effective clinical tools for the assessment of liver status (Navarro and Senior, 2006). AST is found in mitochondria and cytosol of hepatocytes, ALT is localized to the cytosol whereas ALP is found on the sinusoidal surface of hepatocytes (Rosen and Keefe, 2000). LDH is a cytoplasmic marker enzyme whereas GGT is a membrane bound enzyme. Higher serum activities of the aforementioned parameters are often associated with hepatic damage (Kim et al., 2001). This study observed elevations in the serum and liver levels of ALT, AST, ALP, LDH and GGT in a dose-dependent fashion in ATV/r-treated pregnant rats. This observation may be due to the damage of liver hepatocyte membrane leading to the release of the aforementioned parameters into the blood. The measurement of bilirubin is a very sensitive test to substantiate the functional integrity of the liver and severity of necrosis (Singh et al., 1989). This study observed elevations in serum CB and TB levels in a dose-dependent fashion in ATV/r-treated pregnant rats. This may be due to decreased disposal of bilirubin by the liver or the blockade of the excretory duct of the liver.

Reactive oxygen species (ROS) could be toxic or beneficial for cellular functions. The toxic effects of ROS can occur as a result of excess activity due to overload or accumulation leading to oxidative stress (OS). OS plays a major part in the development of chronic and degenerative diseases. Antioxidants such as SOD, CAT, GSH and GPx are inhibitors of OS even at relatively low concentrations, but their functions can be incapacitated by insurmountable activities of ROS
(Sultan, 2014). In this study, hepatic SOD, CAT, GSH and GPx levels were depleted in a dose-dependent fashion in ATV/r- treated pregnant rats. Malondialdehyde (MDA) is a highly reactive three carbon dialdehyde produced as a byproduct of polyunsaturated fatty acid oxidation and during arachidonic acid metabolism for the synthesis of prostaglandins. The monitoring of MDA level in biological systems has been an important indicator of lipid peroxidation (LPO) in-vitro and in-vivo (Janero, 1990). This study observed increases in hepatic MDA levels in a dose-dependent fashion in ATV/r-treated pregnant rats which indicate hepatic LPO. LPO is the oxidative destruction of lipids containing carbon-carbon double bond resulting in lipid peroxyl radicals and hydro peroxides production. Lipid peroxyl radicals and hydroperoxides can stimulate alterations in cell signal transduction and functions leading to cell necrosis and apoptosis, which may facilitate the development of various pathological states (Yin et al., 2011).

Liver histological examination contributes to diagnostic accuracy in drug-induced liver damage and remains a valuable tool for the evaluation of druginduced liver damage. As a clinical test, it provides more information about the state of the liver than any other single assay (Kleiner, 2014). Histopathological examination of the liver of ATV/r-treated pregnant rats showed necrotic hepatocytes at higher doses. The observed necrotic hepatocytes correlate with changes in evaluated biochemical parameters. Hepatic necroses observed in ATV/r-treated rats could be attributed to OS, because OS as a consequence of ROS production can cause progressive modification or degradation of biomolecules such as DNA, proteins, lipids and carbohydrates. This can lead to loss of cell function, cell necrosis and cell death (Halliwell and Gutteridge, 1999).

\section{CONCLUSION}

The use of ATV/r in pregnant women living with HIV may not cause hepatotoxicity at the clinical dose.

Acknowledgments: The authors appreciate the contribution of Mr Eze Ihukumere of the Department of Pharmacology and Toxicology, Faculty of Pharmacy, Madonna University, Elele, Rivers State, Nigeria.

\section{Source of funding: None}

Conflict of interest: The authors declare no conflict of interest.

\section{REFERENCES}

Abdol-Karim Q, AbouZahr C, Dehne K, Mangiaterra V, Moodley J, Rollins N, Say L, e tal (2010). HIV and maternal mortality: turning point. Lancet,375:1948-1949 
Abduljalil K, Furness P, Johnson TN, Rostami-Hodjegan A, Soltani H. (2012). Anatomical, physiological and metabolic changes with gestational age during normal pregnancy: a database for parameters required in physiologically based pharmacokinetic modelling. Clin Pharm, 51: 365-396

Achenbach CJ, Darin KM Murphy RL Katlama C. (2011) Atazanavir/ritonavir-based combination antiretroviral therapy for treatment of HIV-1 infection in adults Fut Virol. 6(2): $157-177$

Ehigiator EB and Adikwu E. (2019) Ethanolic Extract of Chrysophyllum albidum Stem Bark Prevents Alloxan-Induced Diabetes Not Sci Biol, 11(3):325-331

Aebi H,Catalase in vitro," in Method in Enzymology, S. P. Colowick and N. O. Kaplane, Eds., Academic Press, New York, NY, USA. 1984

Bera E, Naidoo D, Williams M. (2012) Maternal deaths following nevirapinebased antiretroviral therapy $S$ Afr J HIV Med,13(4):196-197.

Buege JA, Aust SD. (1978) Microsomal lipid peroxidation. Methods Enzymol, 52: 302-310.

Clark R. Sex (2005) Differences in antiretroviral therapyassociated intolerance and adverse events. Drug Saf, 28: 1075-1083.

Clayden P. (2009). Safety of antiretroviral in pregnancy, South Afric Jour HIV Med. 15-19

Conradie F, Zorrilla IC, Josipovic D, Botes M, Osiyemi O, Vandeloise E et al. (2011). Safety and exposure of once-daily ritonavir-boosted atazanavir in HIV-infected pregnant women HIV Med ,12: 570-579

Coovadia HM, Rollins NC, Bland RM, Little K,Coutsoudis A, Bennish ML, et al. (2007) Mother-to child transmission of HIV-1 infection duringexclusive breastfeeding in the first 6 months of life: an intervention cohort study. Lancet, 31; 369(9567):1107-16.

Eholié SP, Lacombe K, Serfaty L, Wendum D, Girard PM. (2004). Acute hepatic cytolysis in an HIV-infected patient taking atazanavir. AIDS, 18: 1610-1

Eyal S, Easterling TR, Carr D, Umans JG, Miodovnik M, Hankins GD et al. (2010) Pharmacokinetics of metformin during pregnancy. Drug Metab Dispos, 38(5):833-840.

Friedewald WT, Levy RI, Fredrickson DS (1972). Estimation of the concentration of low-density lipoprotein cholesterol in plasma, without use of the preparative ultracentrifuge. Clinical Chemistry 18(6):499- 502.

Gornall A. G, Bardawill C. J. and David M. M. (1949). Determination of serum proteins by means of the biureto reaction.J. Biol. Chem., 177, 751-766.

Halliwell B and Gutteridge JMC. Free Radicals in Biology and Medicine. New York: Oxford University Press; 1999; pp. 1350.

Hamada Y, Nishijima T, Watanabe K et al. (2012) High incidence of renal stones among hiv-infected patients on ritonavirboosted atazanavir than in those receiving other protease inhibitor-containing antiretroviral therapy, Clinic Infect Dis. 55: $1262-1269$.
Hammoud, G. M. and Ibdah, J. A. (2014). Preeclampsia-induced Liver Dysfunction, HELLP syndrome, and acute fatty liver of pregnancy. Clin Liver Dis, 4: 69-73.

Janero DR. (1990) Malondialdehyde and thiobarbituric acidreactivity as diagnostic indices of lipid peroxidation and peroxidative tissue injury. Free RadicBiol Med. 19:515-540.

Joshi D, James, A, Quaglia, A Westbrook, R et al. (2010) Liver disease in pregnancy, 375: 9714; 594-605

Joy S, Poi M, Hughes L, Brady MT, Koletar SL, Para MF, et al. (2005). Third-trimester maternal toxicity with nevirapine use in pregnancy Obstet Gynecol, 106: 1032-1038.

Kim KA, Lee WK, Kim JK, Seo MS, Lim Y, Lee Y, et al. (2001). Mechanism of refractory ceramic bre- and rock wool induced cytotoxicity in alveolar macrophages. Int Arch Occup Environ Health, 74:9-15

Kleiner DE, Chalasani NP, Lee WM, Fontana RJ, Bonkovsky HJ. (2014). Hepatic Histological Findings in Suspected DrugInduced Liver Injury: Systematic Evaluation and Clinical Associations Hepatology. 59(2): 661-670

Lee WM. (1995). Drug-induced hepatotoxicity. NEngl J Med, $333: 1118-27$

Mandelbrot L, Mazy f, Floch-Tudal C, et al. (2011) Atazanavir in Pregnancy: impact on neonatal hyperbilirubinaemia. Eur J Obstet Gynecol Reprod Biol, 157: 18-21

Navarro VJ and Senior JR. (2006) Drug-Related Hepatotoxicity. N Eng J Med,354: 731-739

Rosen HR, Keefe EB. (2000). Evaluation of abnormal liver enzymes,use of liver tests and the serology of viral hepatitis: Liverdisease, diagnosis and management. 1st ed. New York; Churchilllivingstone publishers, 24-35

Rotruck JT, Rope AL, Ganther HF, Swason AB. (1997). Selenium: biochemical role as a component of glutathione peroxidase. Sci. 179: 588-90.

Sedlak, J, Lindsay RH. (1986). Estimation of total, protein-bound and non-protein sulfhydryl groups in tissue with Ellman's reagent. Anal Biochem, 25: 192-205.

Singh B, Saxena AK, Chandan BK, Anand KK, Suri OP, Suri K (1989). Hepatoprotective activity of verbenalin on experimental liver damage in rodents. Fit. 69:135-140.

Sultan S (2014). Reviewing the Protective Role of Antioxidants in Oxidative Stress Caused by Free Radicals Asian Pac. J. Health Sci., 1(4): 401-406

Sun M, Zigma S. (1978). An improved spectrophotometer assay of superoxide dismutase based on epinephrine antioxidation. Anal Biochem. 90: 81-89.

von Hentig N, Dauer B, Haberl A, Klauke S, Lutz T, et al. (2007). Tenofovir comedication does not impair the steady-state pharmacokinetics of ritonavirboosted atazanavir in HIV-1infected adults. Eur J Clin Pharmacol. 63: 935-940.

Wooley, A. Determination-General and reproductive toxicology. In: A Guide to Practical Toxicology Evaluation, Prediction and Risk, 2003, pp. 80-106. Taylor and Francis, New York

YinY, Xu L, and Porter NA. (2011). Free radical lipid peroxidation: mechanisms and analysis Chem Rev, 111; 10; $5944-5972$ 